\title{
Neuroprotective Effect of Sargassum thunbergii (Mertens ex Roth) Kuntze in Activated Murine Microglial Cells
}

\author{
Sung-Gyu Lee and Hyun Kang* \\ Department of Medical Laboratory Science, College of Science, Dankook University, Cheonan-si, Chungnam, 330-714, \\ Republic of Korea \\ *For correspondence: Email: hyunbio@gmail.com, hkang@dankook.ac.kr
}

\begin{abstract}
Purpose: To evaluate the anti-oxidant and anti-neuroinflammatory effects of the Sargassum thunbergii extract (Mertens ex Roth) Kuntze (STE) in lipopolysaccharide (LPS)-stimulated BV-2 microglial cells in vitro.

Methods: STE antioxidative activity was evaluated with an Electron Spin Resonance (ESR) spectrometer, which measured 1, 1-diphenyl-2-picryl-hydrazyl (DPPH) radical scavenging activity. Cell viabilities were estimated using 3-(4, 5-dimethylthiazol-2-yl)-2, 5-diphenyl-tetrazolium bromide (MTT) assays. LPS-stimulated BV-2 microglia were used to study the expression and production of inflammatory mediators, such as nitric oxide (NO), inducible NO synthase (iNOS) and tumor necrosis alpha (TNF- $\alpha$ ).

Results: LPS treatment, following STE pretreatment, decreased NO production by $13 \sim 65 \%$ in a dosedependent manner ( $p<0.001$ at 20,40, 80 and $100 \mu \mathrm{g} / \mathrm{mL}$ ), and was associated with the downregulation of inducible nitric oxide synthase (iNOS) expression. STE also attenuated the TNF- $\alpha$ soluble protein by $16 \sim 47 \%$ ( $p<0.01$ at 20,40 and $80 \mu \mathrm{g} / \mathrm{mL}$ ) in activated murine microglia. Furthermore, the DPPH-generated free radicals were inhibited by STE concentration-dependently.

Conclusion: STE has therapeutic potential in the prevention or treatment of neurodegenerative and oxidative stress-related disorders.
\end{abstract}

Keywords: Sargassum thunbergii, Neurodegenerative diseases, Anti-inflammatory, Microglial cells, Inducible nitric oxide synthase (iNOS), Tumor necrosis factor (TNF)- $\alpha$

Tropical Journal of Pharmaceutical Research is indexed by Science Citation Index (SciSearch), Scopus, International Pharmaceutical Abstract, Chemical Abstracts, Embase, Index Copernicus, EBSCO, African Index Medicus, JournalSeek, Journal Citation Reports/Science Edition, Directory of Open Access Journals (DOAJ), African Journal Online, Bioline International, Open-J-Gate and Pharmacy Abstracts

\section{INTRODUCTION}

Microglia, as immune cells of the central nervous system (CNS), produce a variety of inflammatory mediators in response to immunological stressors, and thus play a critical role in neuroinflammatory processes [1]. Upon activation by exposure to free radicals and lipopolysaccharides (LPS) [2], microglia secrete various bioactive molecules such as nitric oxide (NO), inducible NO synthase (iNOS), interleukins (IL) and tumor necrosis factor (TNF)-a [3]. Over- production of these inflammatory mediators can cause a number of severe neuro-degenerative diseases such as Alzheimer's disease (AD), Parkinson's disease (PD), multiple sclerosis (MS), and Huntington's disease $[4,5]$.

LPS, as the main component of endotoxins, initiates numerous cellular effects that play critical roles in the pathogenesis of inflammatory responses. LPS has been proven to induce microglial activation in response to Gramnegative bacterial infections [6]. These prior 
experiments indicate that LPS-induced stimulation of microglia may be an potent mechanism to study in vitro. Studies have shown that antioxidant and anti-inflammatory agents may inhibit microglial activation, and protect neurons from cell death, a prominent symptom of various neurodegenerative disorders $[6,7]$.

Brown seaweed is a marine organism with antiinflammatory and anti-oxidative effects [8]. Sargassum thunbergii is found along shallow marine coastlines of Korea, and perennially grows on low tide-level rocks of open and sheltered coasts [9]. Sargassum thunbergii, also known as Hede, is also used as a food additive, an anti-helminthic treatment for lumps, dropsy, or swollen and painful scrotums [10].

Studies on Sargassum thunbergii for its beneficial effects on microglia-mediated neuroinflammatory diseases have not yet been reported. The aim of this study was to investigate whether the ethanol extract of Sargassum thunbergii (STE) exhibits protective effects on LPS-activated neuro-inflammatory processes in murine microglial BV-2 cells.

\section{EXPERIMENTAL}

\section{Preparation of Sargassum thunbergii extract (STE)}

Dried plant materials of $S$. thunbergii were purchased from a traditional herb market in Seoul, South Korea and authenticated by taxonomist, Professor Jong-Bo Kim at Konkuk University, South Korea. The S. thunbergii was washed in running tap water, dried at $60{ }^{\circ} \mathrm{C}$ for $24 \mathrm{~h}$ and then ground to a fine powder. The STE was extracted from the fine powder by mixing with $70 \%$ ethanol $(\mathrm{v} / \mathrm{w})$ for $2 \mathrm{~h}$ in a heating mantle at $70 \sim 80{ }^{\circ} \mathrm{C}$. The filtered extract was concentrated by a rotary evaporator (EYELA NVC-2000, Tokyo, Japan) under reduced pressure and lyophilized to produce the supernatant.

\section{Measurement of DPPH radical scavenging activity}

STE antioxidative activity was measured using the stable radical 2, 2-diphenyl-1-picrylhydrazyl (DPPH, Sigma-Aldrich, St. Louis, MO, USA). Samples composed of a reaction mixture of STE aliquots and a DPPH methanolic solution (described previously) [9], each with $60 \mu \mathrm{L}$ of STE and $60 \mu \mathrm{L}$ of DPPH $(60 \mu \mathrm{M})$ in methanol. After mixing vigorously for $10 \mathrm{~s}$, the mixture was transferred to a $100 \mu \mathrm{L}$ Teflon capillary tube. The scavenging activity on the DPPH radical was measured in each sample using a JES-FA ESR spectrometer (Jeol Ltd, Tokyo, Japan). Spin adducts were measured by an ESR spectrometer. Experimental conditions were as follows: central field, $3,475 \mathrm{G}$; modulation frequency, $100 \mathrm{kHz}$; modulation amplitude, $2 \mathrm{G}$; microwave power, $5 \mathrm{~mW}$; gain, $6.3 \times 10^{5}$; and temperature, $298 \mathrm{~K}$.

\section{Cell cultures and viabilities}

Murine microglia BV-2 cells were cultured in RPMI-1640 medium(Invitrogen, Carlsbad, CA, USA), supplemented with $10 \%$ FBS (Hyclone, Logan, UT, USA), $100 \mathrm{U} / \mathrm{mL}$ of penicillin (Invitrogen), and $100 \mu \mathrm{g} / \mathrm{mL}$ streptomycin (Invitrogen) at $37^{\circ} \mathrm{C}$ in a humidified atmosphere of $5 \% \mathrm{CO}_{2}$. In all experiments, cells were pretreated with indicated concentrations of STE for 1 $\mathrm{h}$ before the addition of LPS $(1 \mu \mathrm{g} / \mathrm{mL}$, SigmaAldrich, St. Louis, MO, USA) in serum-free RPMI-1640 medium. Cell viability was determined by 3-(4, 5-dimethylthiazol-2-yl)-2, 5diphenyltetrazolium bromide (MTT) assays, described previously [10]. Cells were incubated with various concentrations of STE for $24 \mathrm{~h}$, followed by MTT for $4 \mathrm{~h} .100 \mu \mathrm{L}$ of isopropanol (in $0.04 \mathrm{~N}$-hydrochloric acid) was then added to the samples to dissolve formazan crystals. The absorbance was read at $570 \mathrm{~nm}$ using the Biochrom Anthos 2010 spectrophotometer (Salzburg, Austria). Cell viability was compared at relative absorbances to the control.

\section{Nitric oxide assay}

NO production assays indicated varying nitrite levels in the STE supernatant using the colorimetric assay with Griess reagent [10]. BV-2 cells were seeded in 6-well plates in $500 \mu$ of the $10 \%$ RPMI-1640 medium, and then stimulated with LPS $(1 \mu \mathrm{g} / \mathrm{ml})$ for $2 \mathrm{~h}$. Fifty microliters of the STE-contained supernatant were combined with the equal volume of Griess reagent (1\% sulfanilamide in $5 \%$ phosphoric acid and $0.1 \%$ naphthyl ethylenediamine dihydrochloride in water). ELISA reader (Bio-Tek Instrument, Winooski, VT, USA) indicated nitrite concentrations (absorbance of $540 \mathrm{~nm}$ ) in comparison to sodium nitrite as control.

\section{Immunoblot analysis}

Murine microglial BV-2 cells were lysed using a buffer containing $20 \mathrm{mM}$ Tris- $\mathrm{HCl}, \mathrm{pH} 7.5,150$ $\mathrm{mM} \mathrm{NaCl}, \quad 1 \mathrm{mM}$ EDTA, $50 \mathrm{mM}$ $\beta$-glycerophosphate, $1 \%$ NP-40 detergent, $1 \mathrm{mM}$ $\mathrm{Na}_{3} \mathrm{VO}_{4}$ and $1 \mathrm{X}$ protease inhibitor cocktail (Complete MiniTM, Roche, Mannheim, 
Germany). Supernatants were collected upon centrifugation of the lysates at $15,000 \times \mathrm{g}$ for 15 $\mathrm{min}$. The concentrations of protein samples were measured using the BCA reagent (Pierce, Rockford, IL, USA). STE-treated cell proteins were separated by sodium dodecylsulphate (SDS) polyacrylamide gel electrophoresis (PAGE) and transferred to PVDF membranes. After blocking with $5 \%$ non-fat milk, the membranes were hybridized at 1:1000 dilutions of primary antibodies for iNOS and $\beta$-actin for 12 $\mathrm{h}$ at $4{ }^{\circ} \mathrm{C}$. Membranes were washed with Tris-Buffered Saline containing $0.1 \%$ Tween-20 (TBST) three times at 5 min interval and hybridized with horseradish peroxidase-conjugated mouse or rabbit secondary antibodies for $1 \mathrm{~h}$ at room temperature. After washing three times with TBST, antigen-antibody complexes were visualized with an ECL Western Blot Detection Kit (GE Healthcare) according to the manufacturer's instructions. The antibodies against iNOS and $\beta$-actin were purchased from Cell Signaling Technology INC. (Beverly, MA, USA).

\section{TNF- $\alpha$ assay}

Murine microglial BV-2 cells $\left(1 \times 10^{5}\right.$ cells/well $)$ were cultured on 96-well plates treated with the STE at indicated concentrations for $1 \mathrm{~h}$ and stimulated with LPS $(1 \mu \mathrm{g} / \mathrm{mL}) .24 \mathrm{~h}$ post-LPS treatment, TNF- $\alpha$ production was determined with cell supernatant using assay kits (BD Biosciences, San Jose, CA, USA) per manufacturer's instructions at room temperature. The optical absorbance was measured at 450 $\mathrm{nm}$ with the ELISA reader.

\section{Statistical analysis}

All data is presented as the mean \pm S.E.M of at least three independent experiments. Statistical analyses were performed using SAS statistical software (SAS Institute, Cray, NC, USA) using one-way analysis of variance, followed by Dunnett's multiple range tests. $P<0.05$ was considered statistically significant.

\section{RESULTS}

\section{STE's effect on DPPH radical-scavenging activity}

As shown in Fig 1A, STE exhibited significant DPPH radical scavenging activity in a dosedependent manner, showing a maximum effect at a concentration of $1 \mathrm{mg} / \mathrm{mL}$. The ESR spectroscopy data at $0.01,0.1$ and $1 \mathrm{mg} / \mathrm{ml}$ was represented in Fig 1B.

\section{STE's Effect on LPS-induced NO production}

STE treatment did not result in cytotoxic overproduction of NO in BV-2 microglial cells treated for $24 \mathrm{~h}$ at concentrations up to $200 \mu \mathrm{g} / \mathrm{mL}$. In all cases of STE treatment, cell viability was above $96 \%$ (Fig 2). In contrast, LPS treatment resulted in excessive production of NO. Pretreatment with STE prior to LPS treatment, however, significantly decreased (by $13 \sim 65 \%$ ) the production of $\mathrm{NO}$ in comparison to LPS-only treatment in a dose-dependent manner (Fig 3). The maximum effect was observed at $100 \mu \mathrm{g} / \mathrm{mL}$ $(p<0.001)$.
A

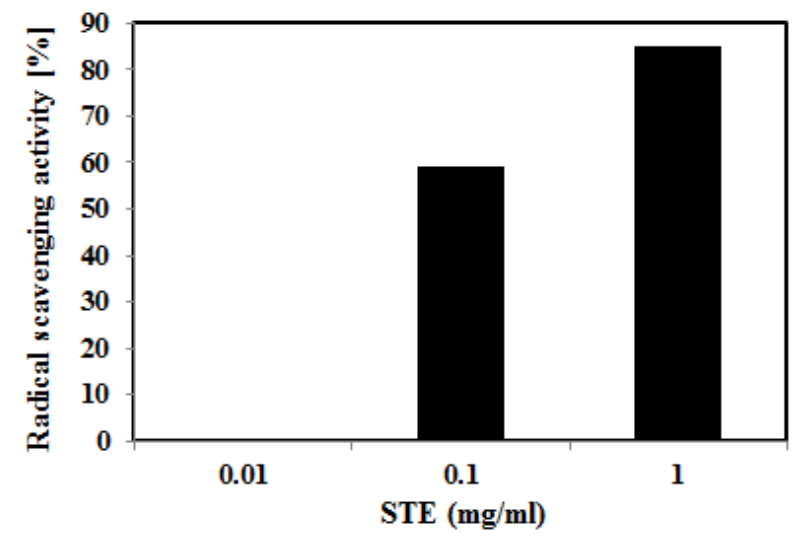

B

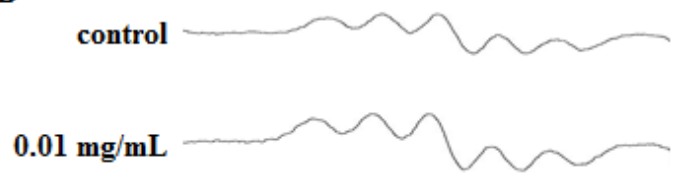

$0.1 \mathrm{mg} / \mathrm{mL}$

$1 \mathrm{mg} / \mathrm{mL}$

Fig 1: Effect of STE on DPPH radical scavenging activity. The capacity to scavenge DPPH free radicals at different concentrations STE (A), shown to vary through ESR spectra (B) measurements. BV-2 cells were treated at various concentrations $(0,0.01,0.1$ and $1 \mathrm{mg} / \mathrm{ml})$. The scavenging activity on DPPH radical measured using JES-FA ESR spectrometer 


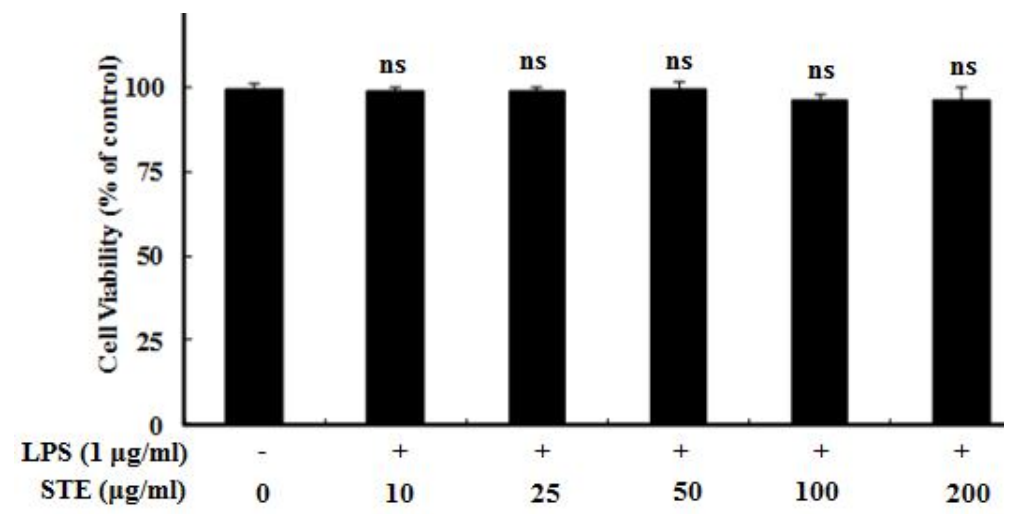

Fig 2: STE's effect on murine microglial BV-2 cells using MTT assay. The results are displayed in percentages relative to control sample without LPS/STE treatment. Data presented is the mean \pm SEM $(n=3)$ for three independent experiments. NS indicates statistical non-significance

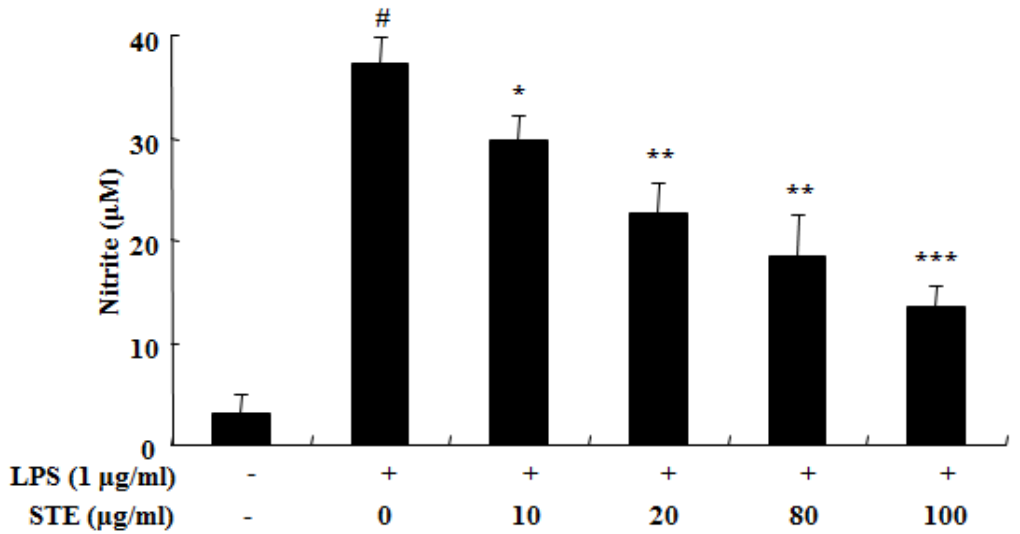

Fig 3: Effect of STE on NO Production in LPS-stimulated murine microglial BV-2 cells. Cells treated with STE at various concentrations $(10,20,40,80$, and $100 \mu \mathrm{g} / \mathrm{ml})$ with or without LPS $(1 \mu \mathrm{g} / \mathrm{mL})$ for $24 \mathrm{hr}$ showed varying cell viabilities. Data presented as the mean \pm S.E.M. $(n=3)$ for three independent experiments. ${ }^{*} p<0.001$, when compared with control group. ${ }^{*} p<0.05$, ${ }^{* *} p<0.01$ and ${ }^{* * *} p<0.001$, when compared with the LPS-only treated control, was assessed by one-way analysis of variance, and then with Dunnett's multiple range tests

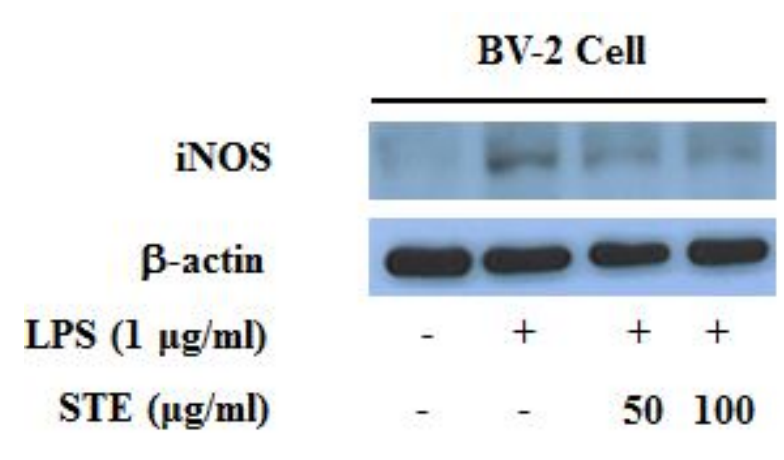

Fig 4: Effect of STE on level of iNOS protein expression in LPS-stimulated BV-2 microglial cells. iNOS production levels in the cells at indicated STE concentrations (50 and $100 \mu \mathrm{g} / \mathrm{mL}$ ) monitored by immunoblot analyses with iNOS antibodies. The internal control used was $\beta$-actin protein expression levels

\section{Effect of STE on LPS-induced expressional levels of iNOS}

STE treatment of murine microglial BV-2 cells exhibited a broad spectrum of inhibitory effects on the expression of iNOS, in contrast to LPS treatment, which enhanced iNOS expression (Fig 4).

\section{Effect of STE on TNF-a production in LPS- stimulated BV-2 cells}

STE significantly inhibited the production of the pro-inflammatory cytokine, TNF-a, in a concentration-dependent manner in LPSstimulated BV-2 cells $(p<0.05$ at $20 \mu \mathrm{g} / \mathrm{mL}$ and $p<0.01$ at 40 and $80 \mu \mathrm{g} / \mathrm{mL}$, respectively). In the LPS-only treatment $(1 \mu \mathrm{g} / \mathrm{mL})$, TNF- $\alpha$ levels were significantly higher than those of the untreated cell control sample $(p<0.001)$ (Fig 5). 


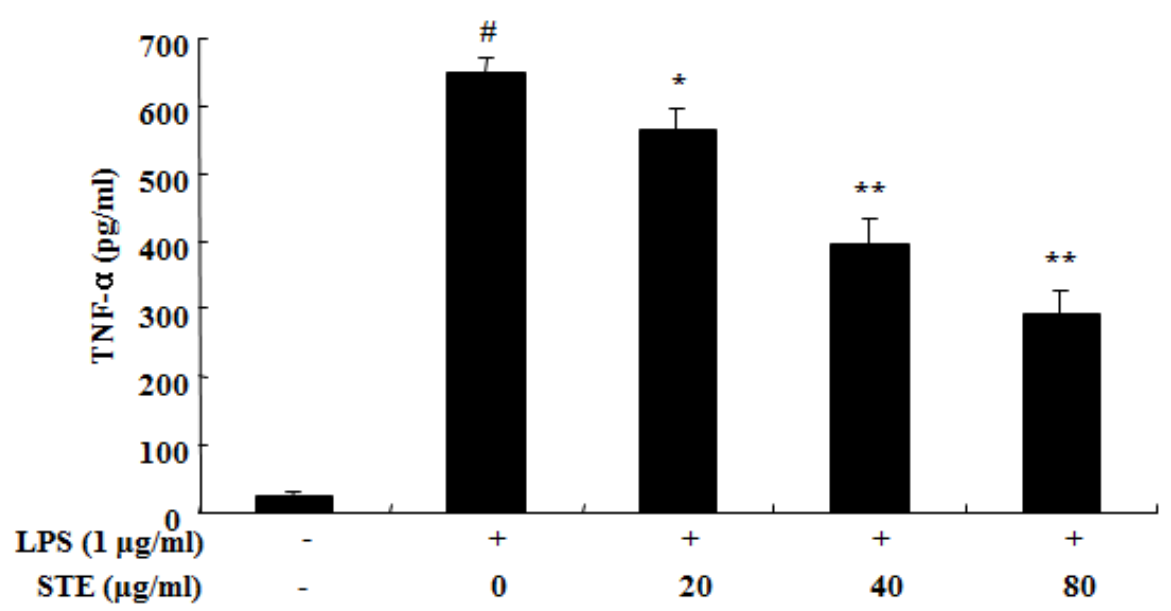

Fig 5: Effect of STE on TNF- $\alpha$ production in LPS-stimulated BV-2 microglial cells. STE's suppression of TNF- $\alpha$ expression at 20, 40 and $80 \mu \mathrm{g} / \mathrm{mL}$ with or without LPS $(1 \mu \mathrm{g} / \mathrm{mL})$ for $24 \mathrm{~h}$. TNF-a levels measured using a murine TNF- $\alpha$ ELISA kit. Data presented are means \pm S.E.M. $(n=3)$ for three independent experiments; ${ }^{\#} p<$ 0.001 , when compared with control group; ${ }^{*} p<0.05$, and ${ }^{* *} p<0.01$

\section{DISCUSSION}

The present study has shown a few antineuroinflammatory effects of STE in murine microglial BV-2 cells, in tandem with LPS (neuroinflammatory) treatment. Although LPS activates TLR4 receptors of microglia to secrete various cytokines, STE treatment STE treatment affects NO, iNOS and TNF-a production and expression in dose-dependent manner. These results show that STE extract has antineuroinflammatory and antioxidative effects.

STE exhibited significant antioxidant activity, as evidenced by the DPPH free radical scavenging method. The DPPH radical assay is a widely used method for evaluating the free radical scavenging activities of several antioxidants in a relatively short period of time [12]. Free radicals and reactive oxygen species (ROS) are important causative factors in the development of age-related neuro-inflammatory and neurodegenerative diseases, [11] so neutralization of free radicals by antioxidants and radical scavengers reduces neuro-inflammation. In our present study, STE significantly affected free radical scavengers, indicating its potential as an antioxidative agent. Many common antioxidants have been effective in reducing neuroinflammation [11], but STE has not studied in activated murine microglial BV-2 cells. Our results present STE's strong potential in reducing neuroinflammatory activity in various neurodegenerative disorders.

In BV-2 microglia cells, NO is generated by the inducible isoform of $\mathrm{NO}$ synthase (iNOS), and has been identified as a neurotoxic substance contributing to central nervous system inflammation [13]. High levels of $\mathrm{NO}$ are produced from L-arginine by iNOS activation in the brain, which prolongs microglial cell activation, and this mechanism is associated with the progression of various neuro-degenerative diseases [14]. Our results clearly show that STE's effect on two elements of this mechanism, as STE attenuates LPS-induced iNOS expression and decreases NO production. STE acts principally on NO generation by downregulating iNOS gene expression at the posttranscriptional level, and can thus prevent the progression of neuro-inflammation.

STE treatment's significant effects on TNF- $\alpha$ expression also indicate STE's therapeutic potential to treat chronic neuroinflammatory diseases. TNF- $\alpha$ is a pro-inflammatory cytokine that initiates the inflammatory response, and its over-production is a possible etiological factor of most neurological disorders [16]. Microglial cell activation by LPS produces various cytokines, including TNF- $\alpha$, which in turn attracts neutrophils and causes the accumulation of neutrophil-secreted proteases and ROS at sites of inflammation. Data from our study shows that STE attenuates production of TNF- $\alpha$, an initiator of the inflammatory response, thereby inhibiting NO production and iNOS expression levels.

\section{CONCLUSION}

These results demonstrate that STE has antiinflammatory properties in LPS-induced BV-2 microglial activation through the down-regulation of inflammation-related gene expression, including iNOS and the proinflammatory cytokine, TNF- $\alpha$. STE's ability to down-regulate key proteins involved in the neuroinflammatory 
response, even combined with LPS, shows its strong potential as a therapeutic agent. STE can be considered as an effective therapeutic and preventative herbal extract for the treatment of several neurodegenerative and oxidative stressrelated diseases.

\section{REFERENCES}

1. Amor S, Puentes $F$, Baker $D$, van der Valk $P$. Inflammation in neurodegenerative diseases. Immunology 2010; 129: 154-169.

2. JK Patra1, NK Dhal2, HN Thatoi3*. In vitro bioactivity and phytochemical screening of Suaeda maritima (Dumort): A mangrove associate from Bhitarkanika, India. Asian Pacific Journal of Tropical Medicine 2011; 727-734.

3. Perry VH, Gordon S. Macrophages and microglia in the nervous system. Trends Neurosci 1988; 11: 273-277.

4. Wirenfeldt M, Ladeby R, Dalmau I, Banati RB, Finsen B. Microglia-biology and relevance to disease. Ugeskr Laeger 2005; 167: 3025-3030.

5. Garden GA, Möller. T Microglia biology in health and disease. J Neuroimmune Pharmacol 2006; 1: 127 137.

6. Xie Q.W., Kashiwabara Y, Nathan C. Role of transcription factor NF-kappa B/Rel in induction of nitric oxide synthase J Biol Chem 1994; 269 (7): 4705-4708.

7. Agullo G, Gamet-Payrastre L, Manenti S, Viala C, Rémésy $\mathrm{C}$, Chap $\mathrm{H}$, et al. Relationship between flavonoid structure and inhibition of phosphatidylinositol 3-kinase: a comparison with tyrosine kinase and protein kinase $C$ inhibition. Biochem Pharmacol 1997; 53: 2087-2094.

8. Yang X, Kang MC, Lee KW, Kang SM, Lee WW, Jeon YJ. Antioxidant activity and cell protective effect of loliolide isolated from Sargassum ringgoldianum subsp. Coreanum Algae 2011; 26: 201-208.

9. Park PJ, Heo SJ, Park EJ, Kim SK, Byun HG, Jeon BT, Jeon YJ. Reactive oxygen scavenging effect of enzymatic extracts from Sargassum thunbergii. J Agr Food Chem 2005; 53: 6666-6672.

10. Donguibogam Committee. Translated Donguibogam. Bubinmunwha Press, Seoul, Koreas; 1999; p 2198.

11. Kim BW, Koppula S, Kim IS, Lim HW. Antineuroinflammatory activity of Kamebakaurin from Isodon japonicus via inhibition of C-Jun $\mathrm{NH}$-terminal kinase and p38 mitogen-activated protein kinase pathway in activated microglial cells. J Pharmacol Sci 2011; 116: 296-308.

12. Finkel $T$, Holbrook NJ. Oxidants, oxidative stress and the biology of ageing. Nature 2000; 408: 239-247.

13. Boje KM, Arora PK. Microglia-produced nitric oxide and reactive nitrogen oxides mediate neuronal cell death. Brain Res 1992; 587(2): 250-256.

14. Murphy S. Production of nitric oxide by glial cells: regulation and potential roles in the CNS. GLIA 2000; 29:1-13.

15. Merrill JE, Benveniste EN. Cytokines in inflammatory brain lesions: helpful and harmful. Trends Neurosci. 1996; 19: 331-338.

16. Zindler E, Zipp F. Neuronal injury in chronic CNS inflammation. Best Pract Res Clin Anaestgesiol 2010; 24(4): 551-562. 